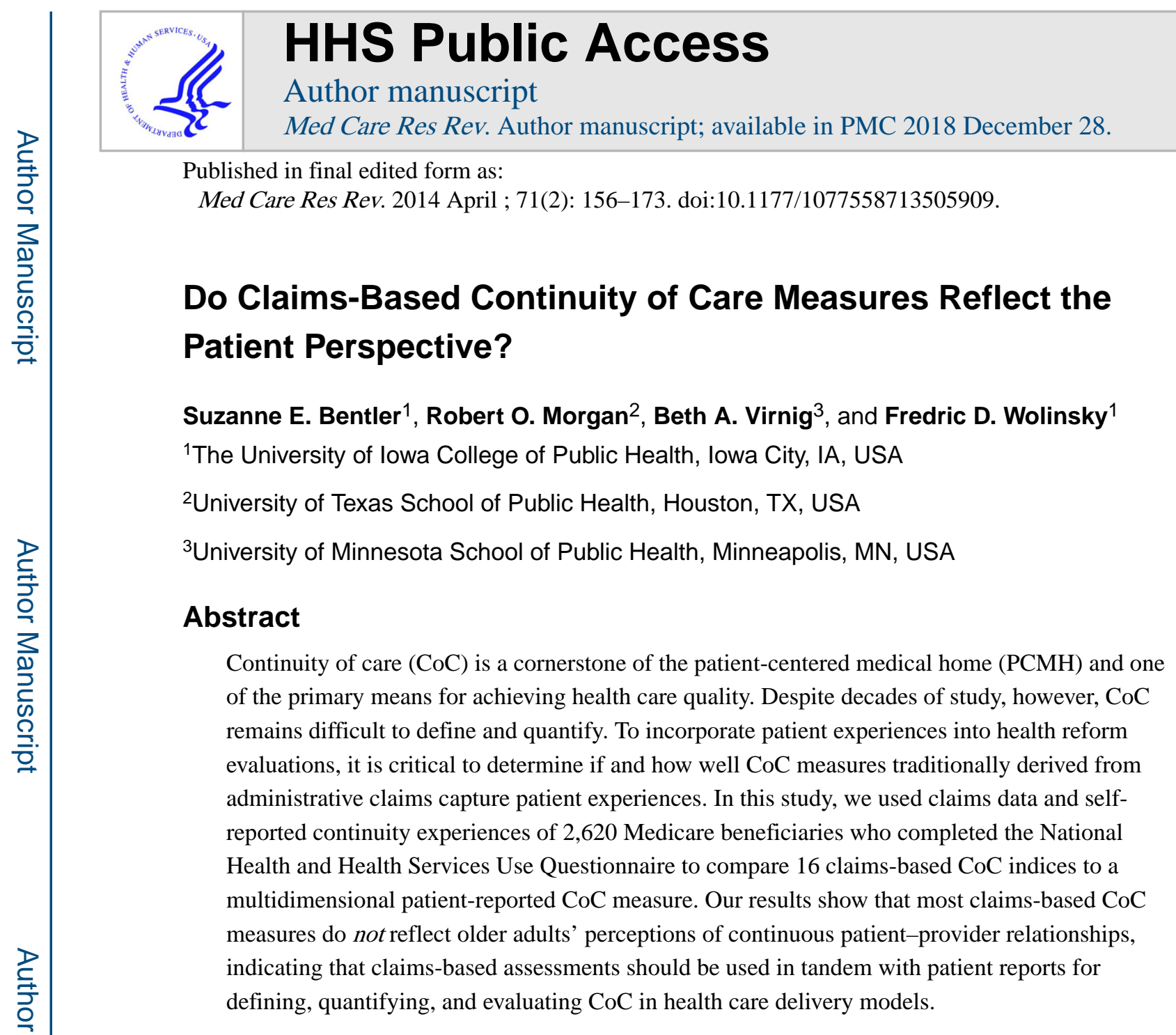

Keywords

continuity of care; patient reports; older adults

\title{
Introduction
}

Continuity in the provision of health services has been identified as a key element of good primary care (Institute of Medicine [IOM], 1996; Starfield, Shi, \& Macinko, 2005), is highly valued by patients (Rodriguez, Rogers, Marshall, \& Safran, 2007; Wasson et al., 1984), and has the potential for improving patient outcomes (Saultz \& Lochner, 2005; Wasson et al., 1984). In 2003, the IOM recommended continuity of care (CoC) as a primary aim for improving health care quality (IOM, 2003), especially for older adults with multiple chronic conditions that require comprehensive medical management. Recent health reform initiatives and policies, including the IOM report about achieving the best care at the lowest cost (IOM,

\footnotetext{
Reprints and permissions: sagepub.com/journalsPermissions.nav

Corresponding Author: Suzanne E. Bentler, Department of Health Management and Policy, The University of Iowa College of Public Health, 105 North River Street, N207-CPHB, Iowa City, IA 52246, USA. suzanne-bentler@ uiowa.edu.

Declaration of Conflicting Interests

The author(s) declared no potential conflicts of interest with respect to the research, authorship, and/or publication of this article.
} 
2012), further highlight the importance of $\mathrm{CoC}$. Moreover, $\mathrm{CoC}$ is a cornerstone of the Patient Protection and Affordable Care Act's (ACA) patient-centered medical home (PCMH) model of health care delivery (Center for Policy Studies, 2007).

Despite its centrality for health policy and decades of study, $\mathrm{CoC}$ remains difficult to define and quantify (Haggerty et al., 2003; Reid, Haggerty, \& McKendry, 2002; Saultz \& Lochner, 2005; Starfield, 1980). Thus, rigorous research that carefully defines and operationalizes the critical components of $\mathrm{CoC}$ is sorely needed for evaluating health system reforms and their effects on patient outcomes. The purpose of this study is to address that need by comprehensively evaluating multiple claims-based measures of $\mathrm{CoC}$ and examine their associations with a recently developed $\mathrm{CoC}$ measure based on patients' experiences.

\section{New Contribution}

We are unaware of any study to date that has looked at the interrelations between several $\mathrm{CoC}$ measures to answer the key question: how do traditional, claims-based measures of longitudinal continuity relate to the duration and quality of the patient-provider relationship from the perspective of older adult patients? Because $\mathrm{CoC}$ is a fundamental component of the $\mathrm{PCMH}$ and other initiatives promoted by the ACA, the ability to rigorously evaluate it using both claims-based and patient-reported experiences is a crucial step for developing a reliable and valid measure. Only with such a measure can the PCMH, ACA, and other health reforms and initiatives be meaningfully evaluated. If claims-based assessments of $\mathrm{CoC}$ adequately capture the experience of patients, then current standards that rely on claims data may be appropriate. If they do not, then the inclusion of patient-reported assessments of $\mathrm{CoC}$ will be needed to provide a more complete picture of care provision. This is especially important for understanding $\mathrm{CoC}$ from the perspective of older adults with multiple chronic conditions (e.g., hypertension, diabetes, heart failure) and aging-related issues (e.g., falls, incontinence, functional and cognitive decline) who require more coordinated and comprehensive health care, which is a hallmark of CoC (Cabana \& Jee, 2004; Weiss \& Blustein, 1996; Wolff, Starfield, \& Anderson, 2002).

\section{Conceptual Framework}

Over the past several decades, hundreds of articles have been published using more than 40 different empirical measures of the $\mathrm{CoC}$ concept. Relatively few studies, however, have provided assessments of the reliability or validity of these indices. In 2003, John Saultz provided a comprehensive review of $\mathrm{CoC}$ measures, resulting in a long-overdue conceptual definition of CoC. Saultz defined $\mathrm{CoC}$ using a hierarchical framework based on providers having enough information about the patient (informational continuity), which facilitates patients having a familiar care setting over time (longitudinal continuity) and culminates in a relationship between the patient and provider characterized by mutual trust and accountability (interpersonal continuity). Several studies have suggested that interpersonal $\mathrm{CoC}$ leads to less intensive care (less hospitalization and emergency department use and better preventive care) and lower costs (Weiss \& Blustein, 1996; Wolff et al., 2002). The underlying assumption is that $\mathrm{CoC}$ allows for interaction and better communication between patients and providers, which fosters a relationship of mutual trust, comfort, and shared information resulting in more accurate provider diagnoses, shared decisions regarding 
treatments, and increased patient compliance and adherence to treatment plans. Thus, interpersonal $\mathrm{CoC}$ is the essence of quality primary care (Freeman, Olesen, \& Hjortdahl, 2003; IOM, 1996; Starfield et al., 2005). It follows, then, that understanding interpersonal continuity is important and requires input from both the patient and the provider.

Most studies, however, have used claims-based measures of longitudinal continuity as a proxy for provider-perceived $\mathrm{CoC}$. This approach assumes that repeated contact with a particular provider is tantamount to having a strong patient-provider relationship. Adequate testing of that assumption has not yet occurred (Reid et al., 2002; Saultz, 2003). Moreover, it is not known whether these proxy measures of the provider perspective are good indicators of either the patient perspective of the duration of the patient-provider relationship (longitudinal continuity) or the quality of the patient-provider interaction (interpersonal continuity).

In 2006, Jee and Cabana expanded Saultz's work by reviewing claims-based CoC indices used in outpatient, primary care settings under the premise that interpersonal continuity is most likely to develop in those settings. They qualitatively assessed the strengths and weaknesses of using $\mathrm{CoC}$ indices to measure provider-patient relationships and, in the process, developed a categorization of the various types of claims-based $\mathrm{CoC}$ indices. Thirty-two different indices used to measure $\mathrm{CoC}$ were identified and classified into five categories: density of visits, dispersion of providers, sequence of provider visits, duration of relationship, and subjective patient estimates. Density indices were the most easily calculated, widely used, and commonly cited (Jee \& Cabana, 2006). They require the identification of a particular provider (e.g., most recently seen, most frequently seen) to serve as the index for quantifying patient visit patterns. Dispersion indices expand density indices by accounting for the variety of providers seen by patients, while sequential indices further expand them by accounting for the order in which different providers are seen. In contrast, duration indices measure the total length of the relationship with one provider and are infrequently used in $\mathrm{CoC}$ studies.

Subjective CoC measures typically require the patient to identify a particular site or provider of care and, by definition, cannot be calculated using claims. In part because of the additional data collection requirements (surveying patients), few $\mathrm{CoC}$ measures reflecting the patient experience were developed until recently (Bentler, Morgan, Virnig, \& Wolinsky, 2013; Gulliford, Naithani, \& Morgan, 2006; Uijen et al., 2011). One of these, the patientreported measure developed by Bentler et al. (2013), has recently been shown to be reliable and factorially valid. It taps the patient's experience of longitudinal continuity with their provider as well as the quality of their interaction during visits.

We used Bentler et al.'s (2013) measure of patient experiences in this research because it was developed using data from the 2,620 Medicare beneficiaries who completed the 2004 National Health and Health Services Use Questionnaire (NHHSUQ; Morgan et al., 2008; Wei, Virnig, John, \& Morgan, 2006). The NHHSUQ survey data were then linked to Medicare claims for comparison of Bentler's measure to a variety of the claims-based $\mathrm{CoC}$ indices to inform the debate about how closely those claims-based indices reflect patient experiences. We used Saultz's (2003) hierarchy and Jee and Cabana's (2006) CoC 
categorizations to frame this inquiry. Carrier and outpatient Medicare claims allowed us to create 15 of the $\mathrm{CoC}$ indices mentioned in the Saultz and Jee and Cabana reviews, as well as one additional $\mathrm{CoC}$ index published afterwards.

In this study, we first evaluated the claims-based indices to confirm the categorizations posited by Jee and Cabana (2006). Second, we examined whether the categories of claimsbased measures correlated with our patient-reported measure. Finally, we used Andersen's behavioral model of health services use (Andersen, 1968, 1995), which categorizes the use of health services as a function of the predisposing, enabling, and need characteristics of the individual to adjust for case-mix. Two hypotheses guided our study. We expected that the patient experience of longitudinal $\mathrm{CoC}$ would relate most strongly to the claims-based density measures because both types of indices are visit-based measures of the duration of care with a specific provider; one derived from patient recall and the other from provider billing. And, we expected little or no relationship between the patient-reported experience of interpersonal $\mathrm{CoC}$ and the claims-based, provider proxy measures because it is unlikely that provider billing adequately captures the quality of the patient-provider interaction experienced by the patient at each visit.

\section{Method}

\section{Sample and Data Sources}

The 2004 NHHSUQ was designed to identify factors affecting Medicare managed care (MMC) plan enrollment. It was mailed to a disproportionately stratified random sample of 6,060 community-residing Medicare beneficiaries 65 years old or older in the fall of 2004 to obtain equal numbers of participants with regard to race/ethnicity (White, Black, Hispanic), Medicare plan type (Medicare fee-for-service [FFS] or MMC), sex, and population density (Morgan et al., 2008). The response rate after adjusting for ineligible survey recipients (e.g., noncommunity residing, moved out of geographic area, or deceased) was $53 \%$

$(2,997 / 5,697)$. Construction of the claims-based $\mathrm{CoC}$ measures focused on the 2,620

Medicare beneficiaries who had complete data for the 13 continuity-related NHHSUQ items and who were likely to have complete Medicare claims for the period 2002 to 2004. There was an average of 3 missing items per person with incomplete data. Among the 2,620 who completed all items, there were slightly more males (51\% vs. $45 \%$ ), Whites (38\% vs. $30 \%$ ), and people who had at least a high school education (65\% vs. 44\%) and slightly fewer Blacks (30\% vs. $38 \%$ ) compared to the 377 who did not complete all items. Because by design half of the NHHSUQ respondents were in MMC plans, they were excluded due to the different billing reporting requirements for Part B (non-institutional) claims (Asper, 2007). Thus, the analytic sample was reduced to the 1,219 people with complete survey responses who had both Part A and Part B coverage and were not enrolled in managed care. Medicare claims were restricted to the 13,896 unique Carrier and Outpatient claims for an Evaluation and Management $(E \& M)$ visit in the year prior to the survey. In sensitivity analyses all Outpatient and Carrier claims (26,046 claims) were used, as were 2 years of claims (48,334 claims, of which 25,899 were E\&M claims). These sensitivity analyses yielded comparable results (available on request). 


\section{Claims-Based Continuity of Care Measures}

Using the Medicare claims, we created nine density indices: six of the eight identified by Jee and Cabana (Current Provider of Care, Current Provider of Care-discounted, Usual Provider of Care, Clinician Index, Site Index, and Herfindahl Index) plus three measures (Continuity Index, Wolinsky Continuity, and Known Provider) from additional literature reviews (Breslau \& Reeb, 1975; Eriksson \& Mattsson, 1983; Mainous \& Gill, 1998; Smedby, Eklund, Anders Eriksson, \& Smedby, 1986; Wolinsky et al., 2007). Six dispersion indices were created: five were identified by Jee and Cabana (2006; Bice-Boxerman CoC, Ejlertsson's K Index, the Modified Continuity Index, Personal Provider Continuity, and the Modified, Modified Continuity Index) plus one (Inverse Number of Providers) from additional literature reviews (Bice \& Boxerman, 1977; Ejlertsson \& Berg, 1984; Magill \& Senf, 1987; Parchman, Pugh, Hitchcock Noel, \& Larme, 2002; Sturmberg, 2002; Sturmberg $\&$ Schattner, 2001). We also created one sequential continuity index (Steinwachs, 1979) identified by Jee and Cabana. We could not create any duration indices using these claims data. All indices were calculated so that higher values represented high levels of continuity. Table 1 provides the categories, definitions, examples, and references for the claims-based $\mathrm{CoC}$ measures created.

\section{Patient-Reported Continuity of Care}

Our patient-reported $\mathrm{CoC}$ measure is a 13-item scale derived from patient responses to a subset of NHHSUQ questions (Bentler et al., 2013). It has four subscales: two tap longitudinal continuity (Care Site and Provider Duration) and two tap interpersonal continuity (Instrumental and Affective). The Care Site subscale had two items asking the respondent if they had a site they visited most often for medical care and, if so, to identify the site (doctor's office, Veterans' Affairs Medical Center, emergency room, or other). The Provider Duration subscale had three items: long-term duration of care at the named site, long-term duration of care with a regular doctor, and short-term duration of care ( within the past year) with the regular doctor. Cronbach's alpha coefficients for the longitudinal continuity subscales of Care Site and Provider Duration were 0.88 and 0.75 , respectively.

The Instrumental subscale had four items that tapped the technical care aspects of the patient-provider relationship. Three of the items (thoroughness of examinations, accuracy of diagnoses, and explanations of medical procedures and tests) were rated on a scale from excellent (5) to poor (1) while the fourth item (knowledge about your health and health care) was rated on a scale from very knowledgeable (4) to not knowledgeable (1). The Affective subscale also had four items tapping the "people skills" aspect of the patient-provider interaction. Two items asked participants to rate "your primary doctor's interest in you" and "your primary doctor's interest in your medical problems" on a scale from excellent (5) to poor (1), one asked respondents to rate their satisfaction with their health care on a scale from very satisfied (4) to very dissatisfied (1), and the fourth asked respondents to rate "How comfortable are you with your primary doctor or with the providers at your usual place of care" on a scale from very comfortable (5) to very uncomfortable (1). The Instrumental and Affective relationship continuity scales had Cronbach's alpha coefficients of 0.88 and 0.87 , respectively. 
Table 2 provides the item counts, mean scores, and intercorrelation between the four subscales and the overall patient-reported $\mathrm{CoC}$ measure. While all of the correlation coefficients among the patient-reported scales were statistically significant, the highest were among the overall $\mathrm{CoC}$ scale and both the Instrumental and Affective subscales. The least correlated subscales were between Care Site and each of the Instrumental and Affective subscales while the other scale relationships were of moderate strength. While the Instrumental and Affective subscales are highly correlated, both theoretically (Ben-Sira, 1980) and in previous empirical work (Bentler et al., 2013), it has been demonstrated that they capture different aspects of interpersonal continuity. Thus, these results indicate that while all subscales tap the overall $\mathrm{CoC}$ construct, they each capture a different domain of the CoC concept.

\section{Covariates}

To obtain the independent effect of the claims-based $\mathrm{CoC}$ measures on the patient-reported $\mathrm{CoC}$ measure, we adjusted for potential confounders available in the NHHSUQ. Measures of predisposing characteristics included patient-reported age (categorized as $\leq 70,71$ to 76 , and >76), sex, race/ethnicity (White, Black, and Hispanic), marital status (married or not), and education (high school education or greater vs. less). We used an indicator of having supplemental insurance (in addition to Medicare) and population density (living in a metropolitan area) as measures of enabling characteristics. Finally, indicators of the need for health services included self-reported smoking status, the SF-8 measure of health-related quality of life (Ware, Kosinski, Dewey, \& Gandek, 2001), and the number of health conditions (e.g., hypertension, diabetes, and stroke).

\section{Statistical Analyses}

SAS Version 9.2 and SPSS Version 20 were used for all analyses. We used means, standard deviations, and Pearson correlation coefficients to describe the $\mathrm{CoC}$ measures. Exploratory factor analysis (EFA) was used to characterize the claims-based $\mathrm{CoC}$ indices. Factors were initially extracted using principal components methods with an oblique factor rotation (oblimin). In sensitivity analyses, we used a promax oblique rotation, and the results were comparable. To determine the appropriate number of factors to retain, we used KaiserGuttman eigenvalue criteria for common factors (Guttman, 1954; Kaiser, 1960), and we required that at least $75 \%$ of the total variation in the items be explained by the extracted factors. Final criteria for our factors involved having at least two indices with primary loadings on each factor, with indices loading on each common factor sharing conceptual meaning (Child, 1990; Tabachnick \& Fidell, 2001).

We used linear regression techniques to evaluate the association between the patientreported (full scale and each subscale) and claims-based $\mathrm{CoC}$ measures. Because all items in the patient-reported $\mathrm{CoC}$ indices do not have the same response set, we first normalized each item by transforming it into a $z$-score. Then, we summed the $z$-scores for each subscale and for the overall scale. This gave each item equal weight in the analyses but advantaged subscales with more items. In sensitivity analyses, we normalized each subscale by taking $z$ scores of its sum (i.e., giving each subscale equal weight) and found comparable results. Factor scores derived from the EFA of the claims-based $\mathrm{CoC}$ indices were used as the focal 
independent variables because each factor score represented a conceptually meaningful claims-based construct and to avoid the multicollinearity that would have occurred if the individual claims-based $\mathrm{CoC}$ indices were used. Each dependent variable (patient-reported CoC, Care Site, Provider Duration, Instrumental, and Affective) was modeled with only the EFA factor scores first and with the addition of the covariates second.

\section{Results}

\section{Sample Characteristics}

The average age was 74 (range $=65-99, S D=7$ ). About half were women, $42 \%$ were White, $30 \%$ were Black, $27 \%$ were Hispanic, and $57 \%$ were married. The majority (60\%) came from urban areas. Less than half (44\%) had at least a high school education, and most (88\%) reported having a supplemental health insurance plan. The majority reported good to excellent health (60\%) and were nonsmokers (91.0\%). Over three fourths (77\%) had at least three health conditions with hypertension (63\%), arthritis (59\%), and hyperlipidemia (49\%) being the most frequently reported.

\section{CoC Measure Characteristics}

Table 2 provides the means and standard deviations of each $\mathrm{CoC}$ index as well as the correlation coefficients between indices. The claims-based index scores ranged from $27 \%$ (Bice-Boxerman $\mathrm{CoC}$ ) to $89 \%$ (Site Index). Aside from the Site Index (which atypically uses site instead of provider type), the highest claims-based continuity score was $62 \%$ for the Known Provider. All 16 of the claims-based CoC measures correlated at the $\searrow 0.30$ level with at least one other claims-based measure, suggesting reasonable factorability (Tabachnick \& Fidell, 2001).

\section{Exploratory Factor Analysis}

Table 3 provides the EFA results for the claims-based $\mathrm{CoC}$ measures. The communalities for each measure were well above 0.30 , indicating shared common variance. The initial eigenvalues showed that the first factor explained almost $54 \%$ of the variance, the second factor almost $21 \%$, and the third factor almost $7 \%$ for a three-factor solution explaining $82 \%$ of the total item variance. All measures had primary factor loadings $\geq 0.69$, although many also had cross-loadings $>0.35$. Thus, the three-factor solution was retained.

The categorizations proposed by Jee and Cabana fit the extracted factors with some exceptions. The Modified, Modified Continuity Index (a dispersion measure) loaded primarily with the density factor (although it had a high secondary loading with the dispersion factor), the Known Provider measure (a density measure) loaded primarily with the dispersion factor, the Sequential Continuity measure loaded with the dispersion factor, and the Site Index ( a density measure) loaded primarily on the third factor but cross-loaded with both the density and dispersion factors. The Wolinsky Continuity measure (not included in the Jee and Cabana review) loaded primarily on the third factor. We labeled Factors 1, 2, and 3 as Concentration, Dispersion, and Longitudinality, respectively, based on the measures driving each. The correlations between the Dispersion factor and the Concentration and 
Longitudinality factors were 0.35 and 0.32 , respectively. The Concentration and

Longitudinality factors were uncorrelated (0.02).

\section{Association Between Patient-Reported CoC and Claims-Based CoC}

Table 4 shows the results from the linear regression models using the claims-based factor scores to predict each of the patient-reported $\mathrm{CoC}$ scales. Panel A shows the results without adjusting for the covariates. The claims-based Concentration factor was only associated with one patient-reported subscale, Care Site $(p=.02)$. The more sophisticated claims-based Dispersion factor was not associated with either the Care Site or the Provider Duration subscales but had some association with both the interpersonal $(p=.02)$ and the full patientreported CoC scales $(p=.04)$. However, the claims-based Longitudinality factor was strongly associated $(p<.001)$ with the patient-reported $\mathrm{CoC}$ scale and all of its subscales at the $p<.05$ level. As shown in Panel $\mathrm{B}$, adjusting for patient characteristics did not appreciably alter these findings.

\section{Discussion}

Accurately determining a patient's care continuity is important for adequately compensating providers (demonstrating $\mathrm{CoC}$ is required in most PCMH models) and for evaluating how $\mathrm{CoC}$ affects patient health outcomes (as prioritized by PCORI). The most commonly used $\mathrm{CoC}$ measures have been claims-based proxies from the provider's perspective (Jee \& Cabana, 2006; Saultz, 2003; Stanek \& Takach, 2010). Indeed, to date little has been known about whether these measures adequately assess the quality of the patient-provider interaction (the essence of good continuity of care) because they do not incorporate patient perceptions. Our results showed that most claims-based $\mathrm{CoC}$ measures were not reflective of patient perceptions of the quality of their provider-patient interaction.

The most widely used claims-based measures are those that identify a particular provider with $\mathrm{CoC}$ based on the concentration of visits with that provider. Health care organizations trying to obtain PCMH recognition from accreditors like the National Committee on Quality Assurance or the Joint Commission are more likely to use concentration measures because they are the easiest to calculate (O'Malley, Peikes, \& Ginsburg, 2008; Stanek \& Takach, 2010). Even though we expected the concentration factor to be somewhat associated with the patient experience of longitudinal $\mathrm{CoC}$ (which includes identification of consistent visits to an identified provider/site), our findings showed that the concentration factor related most strongly with patient perceptions of having a regular site of care and not at all with the consistency or duration of visits. As expected, the concentration factor also had no association with the relationship aspects of continuity. The more sophisticated claims-based dispersion $\mathrm{CoC}$ factor was more strongly related to patient perceptions than the concentration factor, especially regarding the interpersonal aspects of the patient experience of CoC. While not expected, this result may not be surprising considering that people with chronic conditions (who are prevalent in this sample of older adults) may establish care with several different providers to manage their illnesses and, if effective, their patient-provider relationships thrive (Love, Mainous, Talbert, \& Hager, 2004; Nutting, Goodwin, Flocke, Zyzanski, \& Stange, 2003). 
We were somewhat surprised that some claims-based measures were related to the patient experience. The claims-based longitudinality factor was most strongly associated with all components of patient-reported $\mathrm{CoC}$. In post hoc regression analyses, we estimated the relationship between the two individual claims-based indices from the longitudinality factor (the Site Index and Wolinsky Continuity measures) and each of the patient-reported measures. Not unexpectedly, the claims-based Site Index $(b=0.99, p<.001)$ was most associated with the patient-reported Care Site subscale. However, the Wolinsky Continuity measure had stronger independent associations with each of the other patient-reported subscales (Duration $b=1.15, p<.001$; Instrumental $b=0.63, p=.001$; Affective $b=0.47, p$ $=.01)$, while both the claims-based Site Index $(b=2.19, p=.003)$ and Wolinsky measure $(b$ $=2.39, p<.001)$ were significantly associated with the full patient-reported CoC scale. The association with the interpersonal subscales was perhaps the most surprising given the prevailing thought that claims-based measures may not adequately capture the patientprovider relationship (Saultz, 2003; Stanek \& Takach, 2010). The Wolinsky measure, by definition, uses at least 2 years of $\mathrm{E} \& \mathrm{M}$ visit claims to identify continuity, and it may be that this operationalization best conceptualizes what patients consider when visiting their regular provider.

One limitation of this work is that we were not able to calculate every extant claims-based $\mathrm{CoC}$ measure. We were, however, able to recreate the two most commonly used measures (i.e., Usual Provider of Care and the Continuity of Care Index). Another limitation is that we were only able to use the survey data and claims from respondents in FFS Medicare due to differential reporting requirements in managed care Medicare plans. In our previous work (Bentler et al., 2013), we found that the patient-reported $\mathrm{CoC}$ model was factorially invariant between those in FFS versus MMC plans, suggesting that, at least for patient experiences of continuity, there is consistency between plan types. Regardless, because choice of providers may be limited within some (especially closed panel) MMC plans, these findings may not generalize to such managed care arrangements. Finally, the CoC experienced by these older Medicare beneficiaries may not generalize to younger people.

In general, there was a disjuncture between claims-based and patient perceptions of continuity. Given the increased advocacy for the use of patient-reported indicators of quality and outcomes by organizations such as National Committee for Quality Assurance (2011) and Patient-Centered Outcomes Research Institute (2012), but the traditional reliance on administrative claims (O’Malley et al., 2008; Stanek \& Takach, 2010), our results have important implications. Most important, using a mixed method (i.e., both patient reports and administrative claims) when assessing care continuity may be the most valid approach for evaluating how $\mathrm{CoC}$ relates to patient outcomes. While the use of administrative claims may be adequate if the objective is only to evaluate visit continuity, it is clear that only patient reports provide adequate assessments of interpersonal continuity.

That said, some have suggested that in certain settings patient-reports may overestimate visit continuity (Rodriguez, Marshall, Rogers, \& Safran, 2008) or, due to resource constraints, simply may not be obtainable (O'Malley et al., 2008; Stanek \& Takach, 2010). Our findings also have implications for assessing $\mathrm{CoC}$ in situations where using patient reports may not be feasible. In these instances, claims-based proxies such as the Wolinsky Continuity 
measure, which are derived from E\&M visits to particular providers over a longer time period, could be used as valid approximations of the patient experience. In future studies, we will further validate these $\mathrm{CoC}$ measures by using them to predict health outcomes and service use in older adults.

\section{Acknowledgments}

Funding

The author(s) disclosed receipt of the following financial support for the research, authorship, and/or publication of this article: Support to conduct the NHHSUQ survey was from the National Institute on Aging (NIA R01/ AG019284-01A2) and from the Houston VA Health Services Research and Development Center of Excellence (HFP90-020). This work was also supported by funding from an Alvin R. Tarlov \& John E. Ware Jr. Doctoral Dissertation Award and the John W. Colloton Chair in Health Management and Policy at the University of Iowa.

\section{References}

Andersen RM (1968). A behavioral model of families' use of health services. Chicago, IL: Center for Health Administration Studies.

Andersen RM (1995). Revisiting the behavioral model and access to medical care: Does it matter? Journal of Health and Social Behavior, 55(1), 1-10.

Asper F (2007). Medicare managed care enrollees and the Medicare utilization files (Technical Brief, ResDAC Pub. No. TN-009) Minneapolis: Research Data Assistance Center, University of Minnesota.

Ben-Sira Z (1980). Affective and instrumental components in the physician-patient relationship: An additional dimension of interaction theory. Journal of Health and Social Behavior, 21, 170-180. [PubMed: 7391531]

Bentler SE, Morgan RO, Virnig BA, \& Wolinsky FD (2013). Evaluation of a patient-reported continuity of care measure for older adults. Quality of Life Research. Advance online publication. doi:10.1007/s11136-013-0472-z

Bice TE, \& Boxerman SB (1977). A quantitative measure of continuity of care. Medical Care, 15, 347-349. [PubMed: 859364]

Breslau N, \& Reeb KG (1975). Continuity of care in a university-based practice. Journal of Medical Education, 50, 965-969. [PubMed: 1159765]

Cabana MD, \& Jee SH (2004). Does continuity of care improve patient outcomes? Journal of Family Practice, 55, 974-980.

Center for Policy Studies in Family Medicine and Primary Care. (11, 2007). The patient centered medical home: History, seven core features, evidence and transformational change. Washington, DC: Robert Graham Center Retrieved from http://www.graham-center.org/online/etc/medialib/ graham/documents/publications/mongraphs-books/2007/rgcmo-medical-home.Par.0001.File.tmp/ rgcmo-medical-home.pdf

Child D (1990). The essentials of factor analysis (2nd ed.). London, England: Cassel Educational.

Ejlertsson G, \& Berg S (1984). Continuity of care measures: An analytic and empirical comparison. Medical Care, 22, 231-239. [PubMed: 6700286]

Eriksson EA, \& Mattsson LG (1983). Quantitative measurement of continuity of care. Measures in use and an alternative approach. Medical Care, 21, 858-875. [PubMed: 6621116]

Freeman GK, Olesen F, \& Hjortdahl P (2003). Continuity of care: An essential element of modem general practice? Family Practice, 20, 623-627. [PubMed: 14701883]

Gulliford MC, Naithani S, \& Morgan M (2006). Measuring continuity of care in diabetes mellitus: An experience-based measure. Annals of Family Medicine, 4, 548-555. [PubMed: 17148634]

Guttman L (1954). Some necessary conditions for common factor analysis. Psychometrika, 19, 149161.

Haggerty JL, Reid RH, Freeman GK, Starfield BH, Adair CE, \& McKendry R (2003). Continuity of care: A multidisciplinary review. British Medical Journal, 331, 1219-1221. 
Institute of Medicine. (1996). Primary care: America's health in a new era. Washington, DC: National Academy of Sciences.

Institute of Medicine. (2003). Priority areas for national action: Transforming health care quality. Washington, DC: National Academy of Sciences.

Institute of Medicine. (2012). Best care at lower cost: The path to continuously learning health care in America. Washington, DC: National Academy of Sciences.

Jee SH, \& Cabana MD (2006). Indices for continuity of care: A systematic review of the literature. Medical Care Research and Review, 63, 158-188. [PubMed: 16595410]

Kaiser HF (1960). The application of electronic computers to factor analysis. Educational and Psychological Measurement, 20, 141-151.

Love MM, Mainous AG, III, Talbert JC, \& Hager GL (2004). Continuity of care and the physicianpatient relationship. Journal of Family Practice, 49, 998-1004.

Magill M, \& Senf J (1987). A new method for measuring continuity of care in family practice residencies. Journal of Family Practice, 24, 165-168. [PubMed: 3806028]

Mainous AG, III, \& Gill JM (1998). The importance of continuity of care in the likelihood of future hospitalization: Is site of care equivalent to a primary clinician? American Journal of Public Health, 88, 1539-1541. [PubMed: 9772859]

Morgan RO, Teal CR, Hasche JC, Petersen LA, Byrne MM, Paterniti DA, \& Virnig BA (2008). Does poorer familiarity with Medicare translate into worse access to health care? Journal of the American Geriatric Society, 56, 2053-2060.

National Committee for Quality Assurance. (2011). Standards for patient-centered medical home (PCMH) 2011. Washington, DC: Author.

Nutting PA, Goodwin MA, Flocke SA, Zyzanski SJ, \& Stange KC (2003). Continuity of primary care: To whom does it matter and when? Annals of Family Medicine, 1, 149-155. [PubMed: 15043376]

O'Malley AS, Peikes D, \& Ginsburg PB (2008). Qualifying a physician practice as a medical home (Policy Perspective: Insights Into Health Policy Issues; No. 1.31) Washington, DC: Center for Studying Health System Change and Mathematica Policy Research.

Parchman ML, Pugh JA, Hitchcock Noel P, \& Larme AC (2002). Continuity of care, self-management behaviors, and glucose control in patients with type 2 diabetes. Medical Care, 40, 137-144. [PubMed: 11802086]

Patient-Centered Outcomes Research Institute. (2012). Patient-centered outcomes research. Retrieved from http://www.pcori.org/what-we-do/pcor/

Reid RJ, Haggerty JL, \& McKendry R (2002). Defusing the confusion: Concepts and measures of continuity of healthcare. Ottawa, Ontario, Canada: Canadian Health Services Research Foundation.

Rodriguez HP, Marshall RE, Rogers WH, \& Safran DG (2008). Primary care physician visit continuity: A comparison of patient-reported and administratively derived measures. Journal of General Internal Medicine, 23, 1499-1502. [PubMed: 18563492]

Rodriguez HP, Rogers WH, Marshall RE, \& Safran DG (2007). The effects of primary care physician visit continuity on patients' experiences with care. Journal of General Internal Medicine, 22, 787793. [PubMed: 17431698]

Saultz JW (2003) Defining and measuring interpersonal continuity of care. Annals of Family Medicine, 1, 134-143. [PubMed: 15043374]

Saultz JW, \& Lochner J (2005). Interpersonal continuity of care and care outcomes: A critical review. Annals of Family Medicine, 3, 159-166. [PubMed: 15798043]

Smedby O, Eklund G, Anders Eriksson E, \& Smedby B (1986). Measures of continuity of care: A register-based correlation study. Medical Care, 24, 511-518. [PubMed: 3713289]

Stanek M, \& Takach M (2010). Evaluating the patient-centered medical home: Potential and limitations of claims-based data. Portland, ME: National Academy for State Health Policy.

Starfield B (1980). Continuous confusion? American Journal of Public Health, 70,117-118. [PubMed: 7352602]

Starfield B, Shi L, \& Macinko J (2005). Contribution of primary care to health systems and health. Milbank Quarterly, 83, 457-502. [PubMed: 16202000] 
Steinwachs DM (1979). Measuring provider continuity in ambulatory care: An assessment of alternative approaches. Medical Care, 17, 551-565. [PubMed: 449431]

Sturmberg JP (2002). General practice-specific care categories: A method to examine the impact of morbidity on general practice workload. Family Practice, 19, 85-92. [PubMed: 11818355]

Sturmberg JP, \& Schattner P (2001). Personal doctoring: Its impact on continuity of care as measured by the comprehensiveness of care score. Australian Family Physician, 30, 513-518. [PubMed: 11432029]

Tabachnick BG, \& Fidell LS (2001). Principal components and factor analysis. In using multivariate statistics. Boston, MA: Allyn \& Bacon.

Uijen AA, Schellevis FG, van den Bosch WJHM, Mokkink HGA, van Weel C, \& Schers HJ (2011). Nijmegen continuity questionnaire: Development and testing of a questionnaire that measures continuity of care. Journal of Clinical Epidemiology, 64, 1391-1399. [PubMed: 21689904]

Ware JE, Kosinski M, Dewey JE, \& Gandek B (2001). How to score and interpret the single-item health status measures: A manual for users of the SF-8 health survey. Lincoln, RI: QualityMetric.

Wasson JH, Sauvigne AE, Mogielnicki RP, Frey WG, Sox CH, Gaudette C, \& Rockwell A (1984). Continuity of outpatient medical care in elderly men. A randomized trial. Journal of the American Medical Association, 252, 2413-2417. [PubMed: 6481927]

Wei II, Virnig BA, John DA, \& Morgan RO (2006). Using a Spanish surname match to improve identification of Hispanic women in Medicare administrative data. Health Services Research, 41, 1469-1481. [PubMed: 16899019]

Weiss L, \& Blustein J (1996). Faithful patients: The effect of long-term physician-patient relationships on the cost and use of health care by older Americans. American Journal of Public Health, 86, 1742-1751. [PubMed: 9003131]

Wolff JL, Starfield B, \& Anderson G (2002). Prevalence, expenditures, and complications of multiple chronic conditions in the elderly. Archives of Internal Medicine, 162, 2269-2276. [PubMed: 12418941]

Wolinsky FD, Miller TR, Geweke JF, Chrischilles EA, An H, Wallace RB, ... Rosenthal GE (2007). An interpersonal continuity of care measure for Medicare Part B claims analyses. Journals of Gerontology, Series B, Psychological Sciences and Social Sciences, 62, S160-S168. 


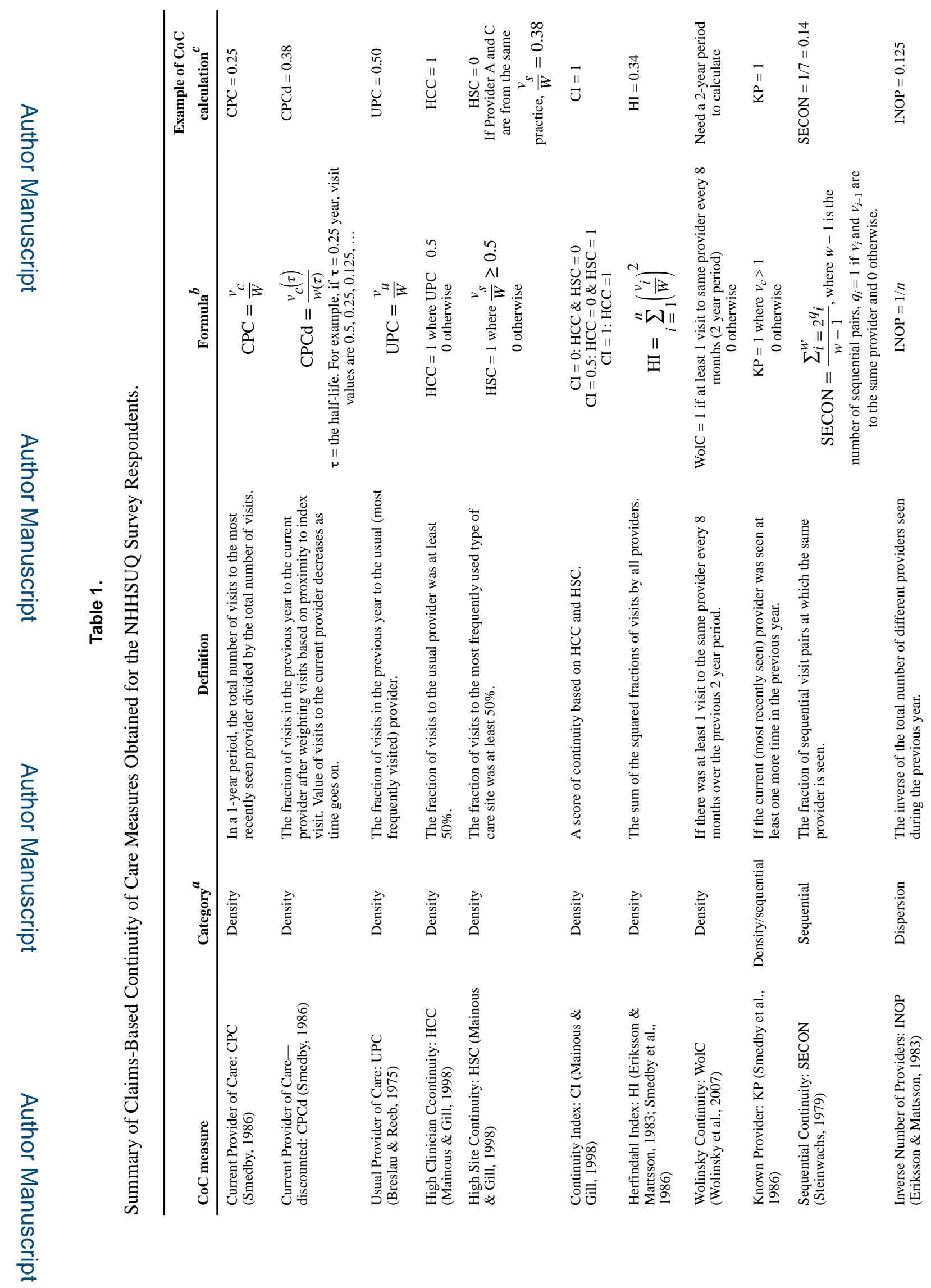

Med Care Res Rev. Author manuscript; available in PMC 2018 December 28. 
Bentler et al.

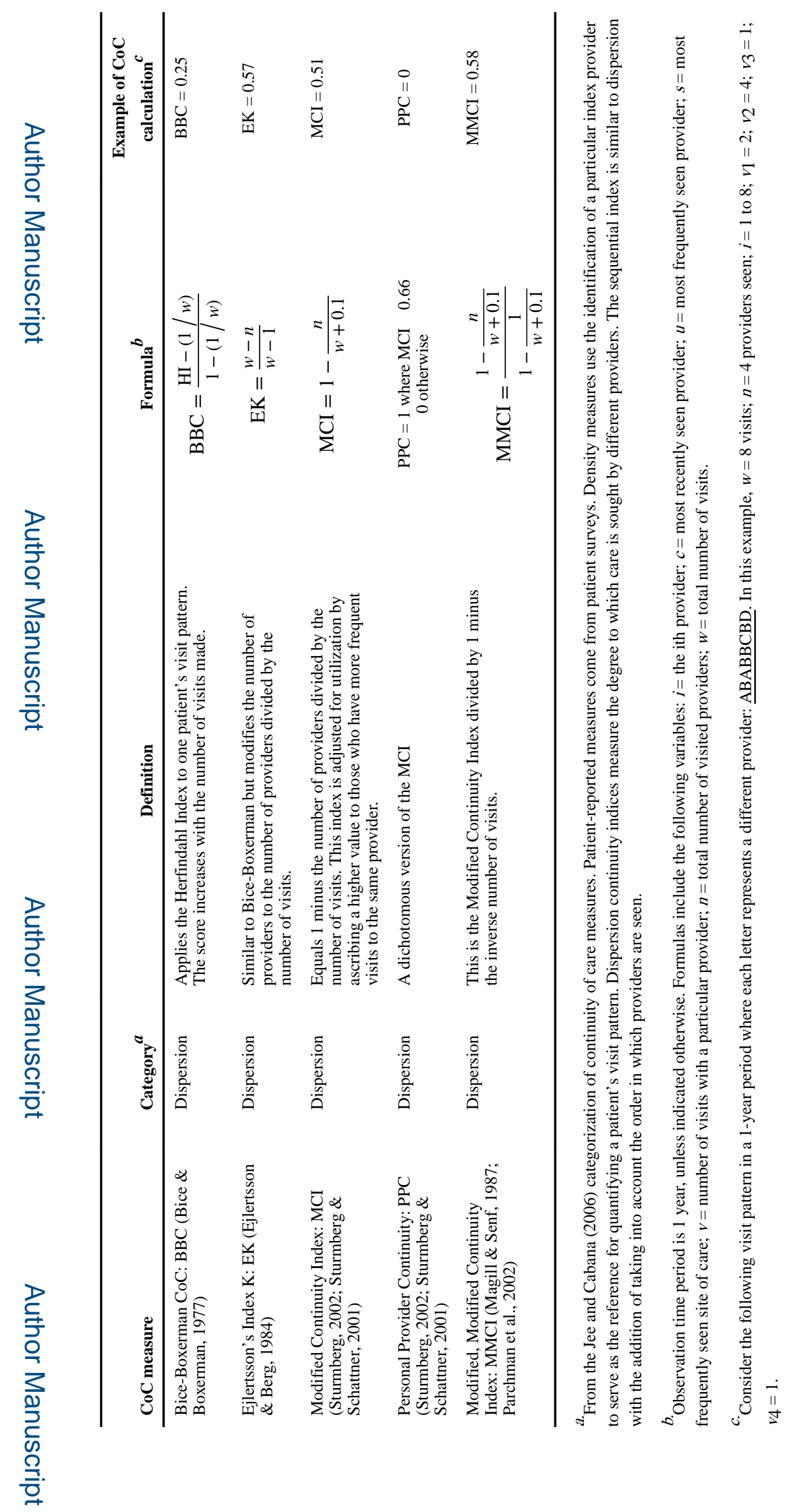

Med Care Res Rev. Author manuscript; available in PMC 2018 December 28. 


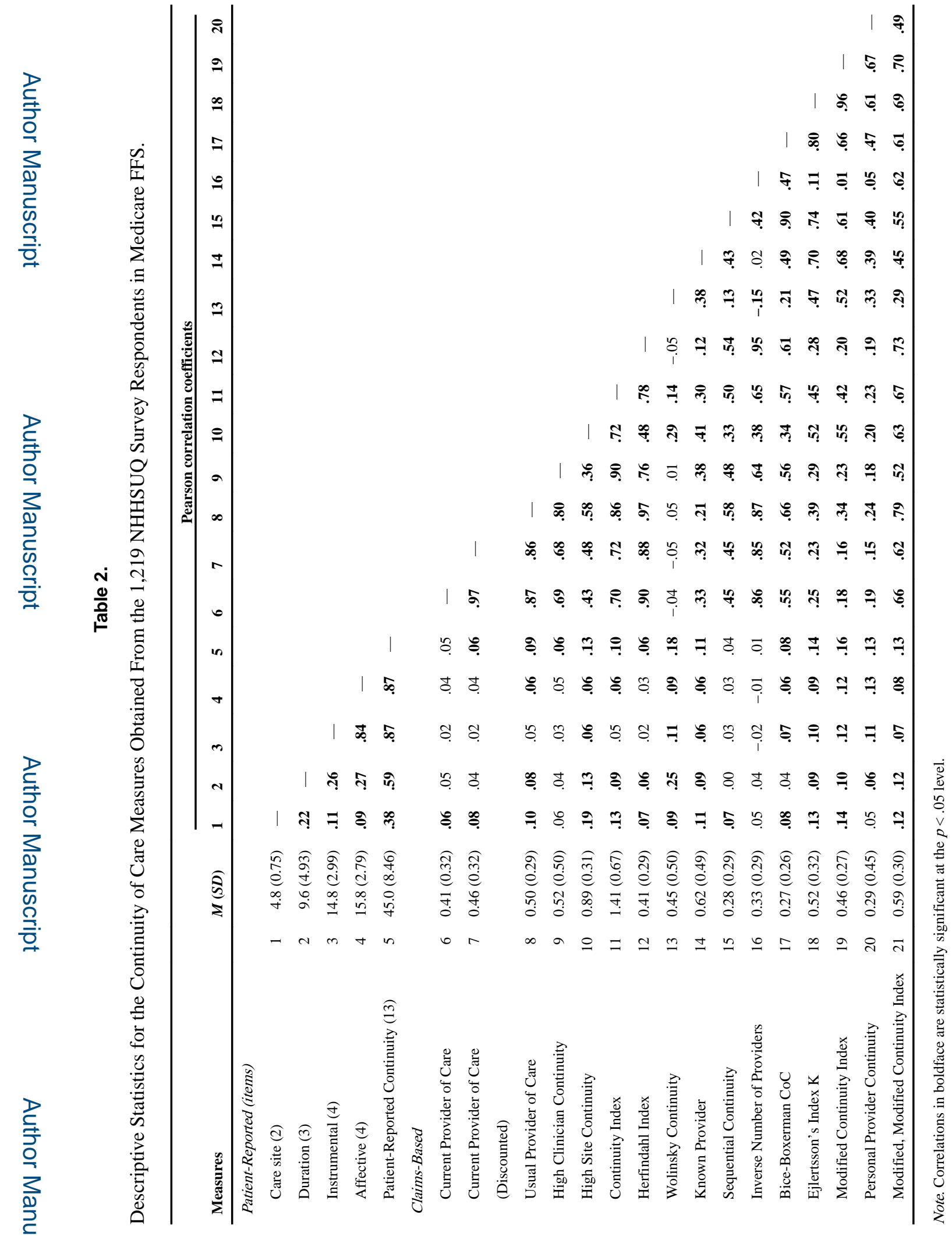

Med Care Res Rev. Author manuscript; available in PMC 2018 December 28. 
Table 3.

Factor Loadings and Communalities Based on a Principal Components Analysis With Oblimin Rotation for 16 Claims-Based CoC Measures ( $n=1,219$ FFS Medicare Beneficiaries).

\begin{tabular}{|c|c|c|c|c|}
\hline \multirow[b]{2}{*}{ CoC measure } & \multicolumn{3}{|c|}{ Loadings } & \multirow[b]{2}{*}{ Communality } \\
\hline & Concentration & Dispersion & Longitudinality & \\
\hline Herfindahl Index & 0.977 & 0.340 & -0.057 & 0.962 \\
\hline Usual Provider of Care & 0.974 & 0.436 & 0.087 & 0.960 \\
\hline Current Provider of Care & 0.926 & 0.321 & -0.010 & 0.859 \\
\hline Discounted Current Provider of Care & 0.925 & 0.294 & 0.011 & 0.857 \\
\hline Number of Providers (Inverse) & 0.920 & 0.169 & -0.157 & 0.891 \\
\hline Continuity Index & 0.865 & 0.435 & 0.314 & 0.838 \\
\hline High Clinician Continuity & 0.824 & 0.341 & -0.007 & 0.684 \\
\hline Modified, Modified Continuity Index & 0.725 & 0.672 & 0.417 & 0.797 \\
\hline Ejlertsson's Index: K & 0.306 & 0.962 & 0.470 & 0.956 \\
\hline Modified Continuity Index & 0.230 & 0.918 & 0.596 & 0.951 \\
\hline Bice-Boxerman Continuity of Care & 0.604 & 0.862 & 0.003 & 0.912 \\
\hline Sequential Continuity & 0.535 & 0.822 & -0.068 & 0.848 \\
\hline Personal Provider Continuity & 0.160 & 0.715 & 0.260 & 0.522 \\
\hline Known Provider & 0.208 & 0.693 & 0.499 & 0.567 \\
\hline Wolinsky Continuity & -0.049 & 0.422 & 0.731 & 0.596 \\
\hline High Site Continuity & 0.557 & 0.400 & 0.700 & 0.783 \\
\hline \multicolumn{5}{|c|}{ Factor statistics } \\
\hline Eigenvalue & 8.58 & 3.31 & 1.09 & \\
\hline$\%$ of Total variance explained & 53.6 & 20.7 & 6.8 & \\
\hline \multicolumn{5}{|l|}{ Correlations } \\
\hline Concentration & - & 0.35 & 0.02 & \\
\hline Dispersion & 0.35 & - & 0.32 & \\
\hline Longitudinality & 0.02 & 0.32 & - & \\
\hline
\end{tabular}

Note. Total variance explained by the three factors $=81.1 \%$. 
Table 4.

Linear Regression of Each Patient-Reported Continuity Scale by the Claims-Based Factor Scores.

\begin{tabular}{|c|c|c|c|c|c|}
\hline Panel A & $\begin{array}{c}\text { Care Site Subscale, } b \\
(S D)\end{array}$ & $\begin{array}{l}\text { Duration Subscale, } b \\
(S D)\end{array}$ & $\begin{array}{c}\text { Instrumental } \\
\text { Subscale, } b(S D)\end{array}$ & $\begin{array}{c}\text { Affective Subscale, } b \\
(S D)\end{array}$ & $\begin{array}{l}\text { Full Patient-Reported } \\
\text { CoC Scale, } b(S D)\end{array}$ \\
\hline Concentration & $0.13(0.05)^{*}$ & $0.14(0.07)$ & $-0.03(0.10)$ & $0.03(0.10)$ & $0.26(0.23)$ \\
\hline Dispersion & $0.05(0.06)$ & $-0.04(0.08)$ & $0.26(0.10)^{*}$ & $0.23(0.10)^{*}$ & $0.50(0.24)^{*}$ \\
\hline Longitudinality & $0.25(0.05)^{t^{t}}$ & $0.54(0.07)^{t}$ & $0.25(0.10)^{*}$ & $0.20(0.09)^{*}$ & $1.24(0.23)^{t}$ \\
\hline Panel B ${ }^{a}$ & $\begin{array}{c}\text { Care Site Subscale, } b \\
(S D)\end{array}$ & $\begin{array}{l}\text { Duration Subscale, } b \\
(S D)\end{array}$ & $\begin{array}{c}\text { Instrumental } \\
\text { Subscale, } b(S D)\end{array}$ & $\begin{array}{l}\text { Affective Subscale, } b \\
\qquad(S D)\end{array}$ & $\begin{array}{l}\text { Full PR-CoC Scale, } b \\
(S D)\end{array}$ \\
\hline Concentration & $0.12(0.05)^{*}$ & $0.13(0.08)$ & $-0.15(0.10)$ & $-0.07(0.09)$ & $0.03(0.23)$ \\
\hline Dispersion & $0.06(0.06)$ & $-0.02(0.08)$ & $0.43(0.10)^{t^{t}}$ & $0.37(0.10)^{\psi}$ & $0.83(0.24)^{\hbar}$ \\
\hline Longitudinality & $0.21(0.06)^{t^{t}}$ & $0.43(0.08)^{\hbar}$ & $0.30(0.10)^{\dagger}$ & $0.26(0.10)^{\dagger}$ & $1.21(0.23)^{t^{t}}$ \\
\hline
\end{tabular}

${ }^{*} p<.05$.

$t_{p}<.01$.

${ }_{p}^{t}<.001$

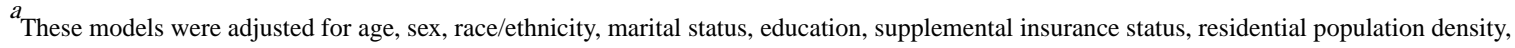
self-rated general health status, number of comorbidities, and smoking status. 